Article

\title{
Characterizing Regenerative Aspects of Living Root Bridges
}

\author{
Wilfrid Middleton ${ }^{1, *}$, Amin Habibi ${ }^{2} \mathbb{(}$, Sanjeev Shankar ${ }^{3}$ and Ferdinand Ludwig ${ }^{1}(\mathbb{D}$ \\ 1 Professorship for Green Technologies in Landscape Architecture, Faculty of Architecture, \\ Technical University of Munich, Arcisstraße 21, 80333 München, Germany; ferdinand.ludwig@tum.de \\ 2 Faculty of Arts and Architecture, Shiraz University, Moaliabad, Shiraz 7188637911, Iran; \\ a_habibi@shirazu.ac.ir \\ 3 Studio Sanjeev Shankar, House No. 4/4, Second Floor, Sweet Abode, Wheelers Road Extension Cross, \\ Cooke Town, Bengaluru, Karnataka 560084, India; sanjeev@sanjeevshankar.com \\ * Correspondence: wilf.middleton@tum.de; Tel.: +49-89289-22570
}

Received: 7 February 2020; Accepted: 10 April 2020; Published: 17 April 2020

check for updates

\begin{abstract}
Living root bridges (LRBs) are functional load-bearing structures grown from Ficus elastica by rural Khasi and Jaintia communities in Meghalaya (India). Formed without contemporary engineering design tools, they are a unique example of vernacular living architecture. The main objective of this study is to investigate to what extent LRBs can be seen as an example of regenerative design. The term "regenerative" describes processes that renew the resources necessary for their function. Whole systems thinking underpins regenerative design, in which the integration of human and non-human systems improves resilience. We adapted the living environments in natural, social, and economic systems (LENSES) framework (living environments in natural, social, and economic systems) to reflect the holistic, integrated systems present in LRBs. The regenerative / sustainable / degenerative scale provided by LENSES Rubrics is applied to 27 focal points in nine flow groups. Twenty-two of these points come from LENSES directly, while five were created by the authors, as advised by the LENSES framework. Our results show 10 focal points in which LRBs are unambiguously regenerative. One focal point is unambiguously sustainable, while 16 are ambiguous, showing regenerative, sustainable, and degenerative aspects. User perspective determines how some focal points are evaluated. The contrast between a local, indigenous perspective and a global, tourism-focused perspective is demonstrated by the results.
\end{abstract}

Keywords: regenerative development; regenerative design; living root bridges; LENSES; vernacular architecture; living architecture

\section{Introduction}

Formed without contemporary design tools, living root bridges are an exceptional example of vernacular architecture that uses the manipulation of tree growth as a building technique. By crossing canyons and rivers, the bridges link homes, fields, villages, and markets, and provide an alternative to often unsuitable contemporary technologies and materials. They can be seen as a highly specific solution for rural connectivity in Meghalaya's geography and climate-high humidity, heavy rains, torrential rivers, and steep, densely forested hillsides. Living root bridges (LRBs) can last for centuries, growing stronger with time in a process that combines periodic human maintenance with natural growth processes. They are deeply integrated with their surroundings, providing slope stability and various ecosystem services [1]. In living wood, an LRB produces its own building material on site, absorbing $\mathrm{CO}_{2}$ over its lifespan. 
LRBs can be seen as a form of architecture that goes far beyond the established concept of sustainable design, which aims to satisfy fundamental human needs today without compromising future generations' prospects [2]. In fact, they seem to be an outstanding example of regenerative design and development. The term "regenerative" describes processes that restore, renew, or revitalize their own sources of energy and materials, creating sustainable systems that combine the needs of society with the integrity of nature [3].

In the following sections, key background to LRBs and regenerative development and design is given, followed by a formulation of this study's hypothesis. The study's methods are then outlined, and results presented and discussed within the wider context of vernacular architectural analysis.

\subsection{Living Root Bridges-The State of Knowledge}

Written documentation of LRBs was sparse until recent years [4]. The first published extensive documentation of LRBs is provided by Ludwig et al. [5]. That study maps 75 bridges (shown in Table 1), discussing their geographic distribution, dimensions, and some key structural characteristics. Eclectic materials, ranging from simple quantifying data (GPS coordinates, basic bridge dimensions, village populations) to qualitative data such as folk stories, photographs, videos, and interviews (e.g., with village headmen and bridge-builders) collected during two research stays in March 2017 and March 2018, contributed to this documentation. The present study draws on the same information and considers the same 75 bridges. Chaudhuri et al. [6] and Shankar [7] describe the societal setting of the bridges and their construction methods. Middleton et al. [8] present photogrammetry as a documentation technique that captures the geometric complexity of LRBs. A deep well of literature on Khasi history and culture provides useful background. Bareh's The History and Culture of the Khasi People provides a well-researched introduction to Khasi culture [9]. An extensive literature review on Khasi philosophy is provided by Malngiang [10], while Lyngdoh [11] contrasts traditional Khasi ecological frameworks with contemporary Cartesian dualism. For a deeper understanding of the key interactions between Khasi culture, community structures, and ecology, see Chakraborty's review of Kynpham Sing Nongkynrih's The Yearning of Seeds $[12,13]$ as well as Shangpliang's description of the traditional position of forests in Khasi society [14]. Tiwari et al. [15] and Cajee et al. [16] discuss Khasi community forest management systems and their social and environmental roles; Tiwari et al. [17] and Ormsby [18] focus specifically on the Sacred Grove system.

Table 1. The 75 bridges relevant to this survey (names provided by the authors of [5], many of which are debated) categorized by extent of use for tourism. Increased use for tourism can result in changes to the bridge and associated community or landscape. Further information about these bridges is provided by [5].

\begin{tabular}{|c|c|c|}
\hline Traditional Use & Minor Tourism Use & Major Tourism Use \\
\hline
\end{tabular}


Table 1. Cont.

\begin{tabular}{cccc}
\hline \multicolumn{1}{c}{ Traditional Use } & Minor Tourism Use & Major Tourism Use \\
\hline Arch Bridge & Rynsiet & & \\
Darrang 1 & Sohkhmi 1 & & \\
Darrang Broken & Suktia 1 & & \\
Diengsiar 1 & Thangkyrta 1,2 & Burma 1 & \\
Halfway Nongbareh & Tynrong 1 & Iar Soh Liang & Nongriat Double-Decker \\
Kudeng Rim 5, 8 & Tyrngei 1 & Kongthong 2 & Mawkyrnot Long Bridge \\
Laitiam 1,2 & Wah Kdal & Kongthong 3 & Mawsaw Hybrid \\
Long Ti Uyiang & Wah Lar Ung & Kudeng Double Decker & Mawsaw Old \\
Lyngsteng 1Mawkliaw & Lyngkhen & Niah Li Bridge & Nongriat Access \\
1,2 & Wah Lynseng & Rangthylliang 4 & Nongthymmai 1 \\
Mawlam 3 & Shoh Klea & Rangthylliang 5 & Nongthymmai 2 \\
Mawshken 1 & Wah Soh Mad & Rangthylliang 6 & Nongthymmai 3 \\
Nongbareh 1 & Wah Soh Shiat & Rangthylliang 7 & Rangthylliang/Mawkyrnot 2 \\
Nongpriang 3 & Wah Spit & Rangthylliang 8 & Siej \\
N'thymmai Old & Wah Surah & Ummonoi & Wah Thyllong \\
Pdei Kongtim 1 & Tiah Long & Wah Amlohmar & \\
Rimai Bridge & Wah Tumbai & Wah Koh La 1 & \\
Rymmai 1 & Um Thliem & Wah Kol La 2 & \\
Rangthylliang 1,2,3,10,11,12,13 & & \\
Nongbah/Mawshuit1 & & \\
Wah Matieh Lower \& Upper & & \\
\hline
\end{tabular}

Ficus elastica grows abundantly in the Khasi and Jaintia Hills $[17,19]$. To initiate the growth of a living root bridge, a branch of Ficus elastica is typically planted on one or both banks of a canyon or river. After the tree reaches an adult stage, aerial roots emerge from the branches. These are trained across a deadwood framework (usually bamboo), and finally implanted in the opposite bank. These roots thicken and produce daughter roots, which are trained similarly. During this process, the bridge builders closely intertwine the roots with each other or with branches, roots, or trunks of the same or another F. elastica tree in order to initiate inosculations, producing a densely interwoven, and often framework-like structure (Figure 1b). The time it takes until the living structure can bear sufficient loads and can be used safely depends on a number of factors, e.g., overall span, exposure to sunlight, soil quality, altitude, or regularity of maintenance. Generally speaking, it can be said that the time span from planting a sapling to full usability is in the range of several decades.
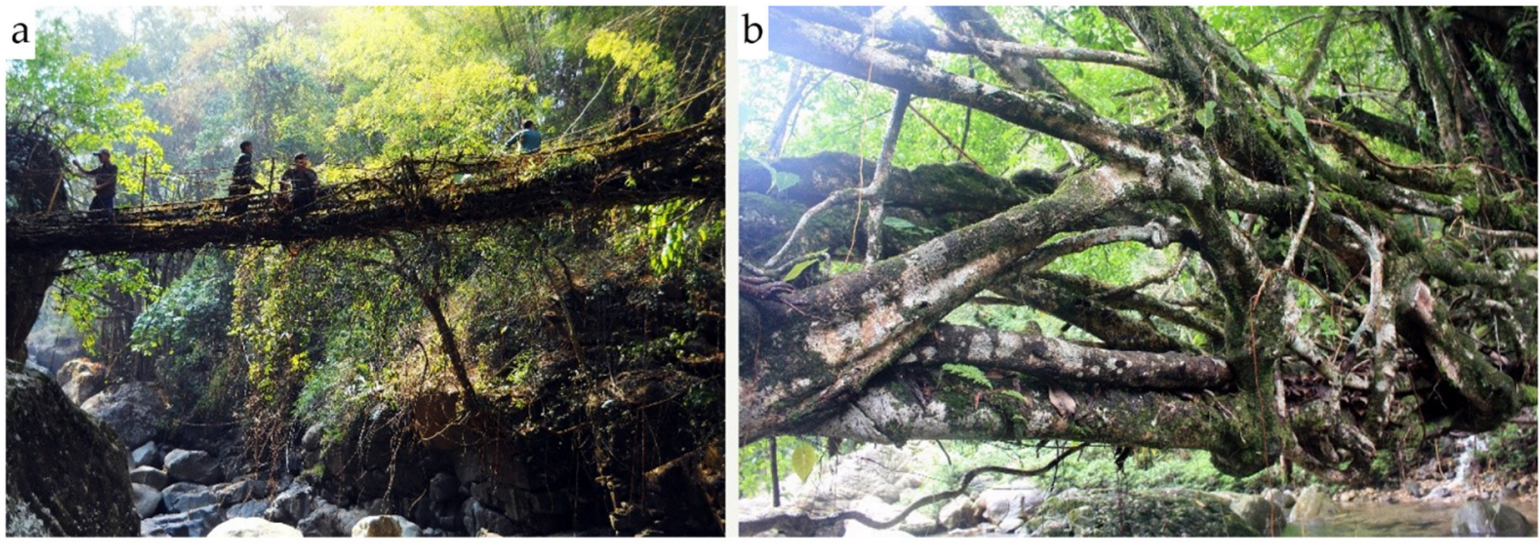

Figure 1. (a) A living root bridge during maintenance (photo: Patrick Rogers) (b) detail of the framework-like load bearing structure of another bridge.

From Ludwig et al.'s study [5], it is clear that village oral histories and discussions with communities provide key insights into the bridges' positions in society and, in particular, into people's attitudes towards the bridges. That study also notes the LRBs' variety, including a wide range of structural systems, ages, dimensions, and settings. In structural terms, the bridges are comparable to compression 
arches, suspension bridges, and simple beams in single and multiple spans, as well as many other forms. Bridge age estimates are generally poor. Bridges with age information can be sorted into three simple categories: Bridges grown by people living today, bridges that were grown by known recent ancestors, and bridges that are known to be very old but with no known histories other than those tied to village histories. Interviews suggest that floods, fires, and landslides destroyed many bridges grown in the past.

A common theme in LRBs is their environmental setting: The vast majority of bridges (68 of 71 geolocated in [5]) grow on forested valley slopes, while the other three grow on areas of the Shillong Plateau. The bridges generally allow access to farmland for village communities based on the plateau, or access to the plateau for villages in the valleys.

Maintenance consists of a variety of techniques: Removal of mosses and epiphytes, pruning and tying of roots, laying of material (stones, soil) on the path, or clearing of the associated path (see Figure 1a). Through interviews and observation, diverse maintenance regimes are documented: Maintenance is conducted by individuals or families, shared amongst a village community, or shared by a consortium of several communities. The extent of maintenance is usually related to use. Bridges that are crossed many times a day receive a large amount of collective attention from users, while those that are left unused are hardly cared for, become overgrown, and lose their stability and functionality over the years. Nowadays, with the influx of tourists to the region, some bridges experience more (but not always more adequate) maintenance than others.

To provide a basic understanding of the relative importance of tourism (at the time of writing this paper), the 75 studied bridges are presented in Table 1, grouped into three categories according to their traditional or tourist use: Bridges that are predominantly used for traditional purposes, bridges with some tourist activity that have seen some changes, and those that have seen major changes. Fifty of the 75 documented bridges $(66 \%)$ are in the first category, $15(20 \%)$ in the intermediate category, and $11(14 \%)$ are significantly changed by tourism (third category). While the regional shift is towards tourism, some traditional use still exists in all bridges. Wah Thyllong bridge, for example, is visited by hundreds of tourists each day, but is still used by farmers, market sellers, and school students. Basic adaptations to tourism are for example preparations within the community to cater for, guide, and accommodate visitors. Alongside this, bridges are reinforced for tourists' safety. In the course of further increasing tourism guesthouses are built, paths to the bridges are adapted or replaced by roads, and farming is scaled down as income is generated from tourism.

\subsection{Beyond Sustainability—Regenerative Development and Design}

Sustainable development is typically defined as "development that meets the needs of the present without compromising the ability of future generations to meet their own needs" [2]. This definition from the Brundtland report in 1987 has become the basis for international environmental agreements and laws. In the three decades since, several authors have questioned if sustainability alone is sufficient to ensure a livable future for a rapidly growing human population [20-22]. In fact, the last decades witnessed a radical exploitation of natural resources, a mass extinction of species, and a destruction of ecological systems [23]. Sustainability, focusing on resource efficiency and minimizing environmental damage and human health risks may slow down or halt the degradation of the planet's natural systems, but seems unable to solve the pressing problems of an already seriously disturbed planet.

Regenerative design and regenerative development directly address the shortcomings of the sustainability paradigm. Lyle [24] defines regenerative design as the replacement of linear systems of throughput flows with "cyclical flows at sources, consumption centers, and sinks." Mang and Reed [25] distinguish regenerative development from design. Regenerative design entails active building of the self-renewing system components. Regenerative development is twofold: Identification of phenomena for fruitful regenerative design and cultivation of evolving systems in which users become designers, thus integrating design to the regenerative system. The historical foundations of regenerative design and development are comprehensively covered by [26]. As outlined by Mang 
and Reed in Regenerative Development and Design [25], the regenerative approach is directly based on McHarg's book Design with Nature [27], which lays the foundation for the ecological view of urban landscape design. Much of the inspiration for regenerative design is drawn from the relationships and adaptations of indigenous peoples to their ecosystems [27]. Mollison and Holmgren developed permaculture as an ecological design system to promote design of human habitats and food production systems based on the relationships found in natural ecological communities (see [28,29] for a deeper discussion of permaculture). Although these approaches already contain many regenerative aspects, regenerative design and development did not emerge as an independent discipline until the 1990s. Lyle's Regenerative Design for Sustainable Development [24] provided the first comprehensive articulation of, and handbook for regenerative design. It laid out the framework, principles, and strategies for a design system aimed at reversing the environmental damage caused by what Lyle called "industrial land use practices". Regenerative systems provide for "continuous replacement, through [their] own functional processes, of the energy and materials used in their operation."

Regenesis Group extend regenerative concepts from design to create the theoretical and technological foundation for regenerative development, forming the distinction stated above. A typical example of regenerative development as articulated by Regenesis and Lyle is the role of humans as influential participants in the health of the earth's web of living systems [25]. As Cole [30] puts it, this runs anathema to the Cartesian-Newtonian worldview dominant in western-globalized societies, which "implicitly places human enterprise dominant over and essentially independent of nature". Regenerative approaches seek not only to reverse the degeneration of the earth's natural systems, but also to design human systems that can coevolve with natural systems-evolve in a way that generates mutual benefits and greater overall resilience [25].

In recent years, a number of design tools and frameworks were established to support regenerative design and developmental processes. The author of [26] gives a summary of five well-established tools: REGEN, Eco-Balance, living environments in natural, social, and economic systems (LENSES), Perkins+Will Framework, and Living Building Challenge. That comparative study concludes that LENSES is the most comprehensive tool in addressing regenerative goals and the only one that is developed as a process-based approach as well as a metrics tool.

The LENSES (living environments in natural, social, and economic systems) Framework was developed by the Institute for Built Environment at Colorado State University and the Rocky Mountain Institute to be "a guidance tool that will lead users to appropriate, contextual, and regenerative decisions and actions" [31]. Currently, it is managed by CLEAR (center for living environments and regeneration). The intention of this framework is "to shift mind-sets toward regenerative thinking and to inspire positive action throughout the life cycle of a project". It focuses on 'descriptive metrics' instead of 'prescriptive metrics' and can be applied across project types on all scales [25]. Specific solutions are not predetermined; the framework rather assists people through an intentional process of discovery and allows access to a range of tools, as exemplified by the variety of configurations presented in previous studies [31-33].

\subsection{Main Aim of This Research}

The hypothesis of this study is that LRBs effectively fulfil the above definition of regenerative design and development [25]. It aims to evaluate how far and in which aspects this is the case. With this in mind, LENSES - applied here as a metrics tool using the Rubrics worksheets-was chosen as a methodical basis for the study.

\section{Materials and Methods}

\subsection{Developing an Appropriate Metric Tool}

LENSES is a system made up of three interrelated layers or 'lenses', each acting as a visual aid to help ground concepts. The three lenses—vitality lens, flows lens, and foundations lens-perform individual 
functions. The main aim of the vitality lens is to identify degenerative, sustainable, and regenerative (DSR) aspects as well as leverage points within the design process of a project. The flows lens promotes a deep understanding of the context of a project with a focus on key patterns and relationships. Graphically, it shows interrelated aspects of a system that make up the whole. The foundation lens is designed to engage users in creating a shared sense of commitment, to define guiding principles within the context of a project. Two lenses-vitality and foundations lenses-refer more to the planning process, while the flows lens has a greater focus on project assessment. As mentioned above, this study is specifically focused on assessment. Therefore, only the flows lens, and within it the LENSES Rubrics tool, is used here.

The flows lens groups focal points into flows. CLEAR [34] provides 11 flows, which are detailed in the Rubrics. It also suggests adding or taking away flows, according to need. In general, CLEAR describes the structure of the three lenses less as a fixed system and more as an open source resource. The flows relevant to LRBs were discovered during the evaluation process. They are described and further explained in Section 2.2.

The LENSES Rubrics are charts providing a qualitative analysis of focal points within each flow [34]. The main aims of the Rubrics are to evaluate the project's existing state, acknowledge areas for improvement, and continually assess the impact of project decisions. They can be used either in concert with the LENSES process or as a stand-alone resource to establish an understanding of what characteristics and qualities define DSR aspects of a project. They are used here for the latter function, as continual assessment of decisions is not a focus of this study (see discussion).

Within the Rubrics, statements that range from degenerative to regenerative are provided for each focal point, against which the user evaluates the project. Figure 2e shows the Rubric worksheet for the flow 'Beauty' as an example. For each focal point, relevant statements in the Rubrics were highlighted by the authors. From this, a position on the DSR spectrum was identified. Whenever statements from the Rubrics worksheets are directly quoted in the text, they are put in quotation marks without giving further references.

During the evaluation, it became clear that the assessment results largely depend on the user perspective. Two key perspectives were identified: The traditional makers and users on the one hand and the globalized viewpoint of researchers or tourists on the other. To provide a basic understanding of the balance of these perspectives, Table 1 shows the proportion of bridges impacted by tourism. These contrasting perspectives are useful in analysis, though it must be stated that they are a theoretical assumption. They do not represent a true user experience since this depends upon a complex mix of cultural, social, and technological inputs. In Figure 2e, examples of sections of text relevant to each of these perspectives are marked in red. For discussion of this perspective with respect to the regenerative paradigm, compare $[35,36]$.

The authors chose to include these potentially contrasting perspectives, which led to occasionally contradictory results. To represent the system as a whole whilst preserving the contradictions present within each focal point, a new graphic representation was developed. Each focal point is shown as a circle segment, which together form a whole circle, similar to the petals in the CLEAR flow lens [37]. The evaluated position is represented with a black line and the range of relevant statements is shaded. Narrow shading represented less ambiguity in the results. For example, Figure 10 shows four focal points-Outdoor Comfort and Microclimate is less ambiguously regenerative than Equity and Inclusivity or Physical, Mental, and Spiritual Balance, while Healthy Lifestyles is the most ambiguous. The aim of the diagram is to retain detail whilst allowing a summative view. Figure 2 shows the aspects of LENSES used in this study and how the system was adapted. The numerical values given in the original Rubrics ( -3 for degenerative, 0 for sustainable, +3 for regenerative) were thought to infer a precision that is both unnecessary in this study and misleading. 


\section{a}

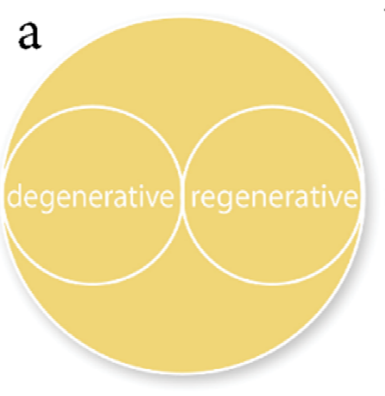

$\mathrm{e}$ $\mathrm{b}$

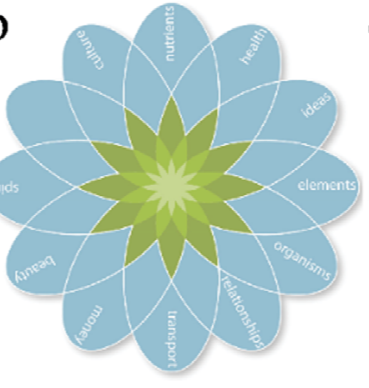

C

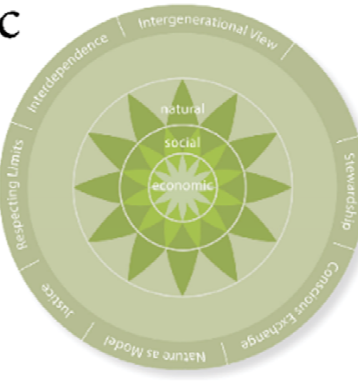

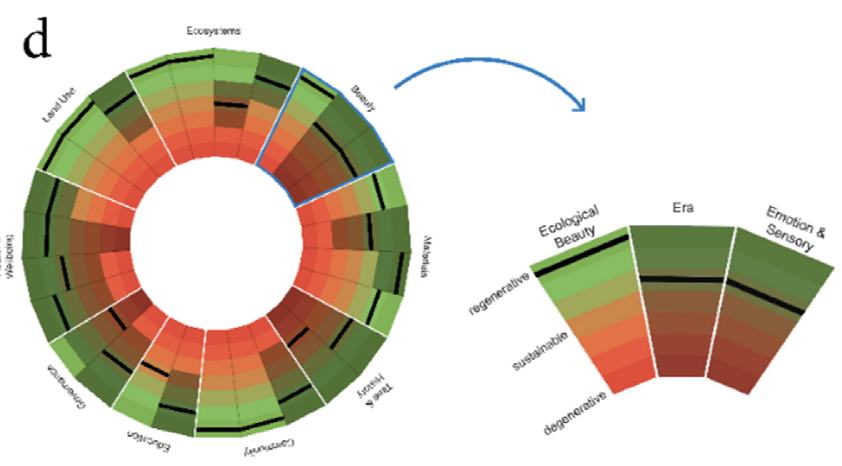

degenerative sustanable regenerative

beauty

\begin{tabular}{|c|c|c|c|c|c|}
\hline focal point & degenerate & & sustain & + & regenerate \\
\hline $\begin{array}{l}\text { Ecological } \\
\text { Beauty } \\
\text { The assthertic expression of } \\
\text { the web of life between all } \\
\text { living things. }\end{array}$ & $\begin{array}{l}\text { Design obstructs biophilia; creates } \\
\text { an cntirily synthetic cenvironment } \\
\text { disconnected from ecological } \\
\text { contexti prohibitis abblity to } \\
\text { appreciate local ecological system. }\end{array}$ & $\begin{array}{l}\text { Desigrn rininimally considers } \\
\text { biophilia; attempts to integrate } \\
\text { ecological context or scale of place. }\end{array}$ & $\begin{array}{l}\text { Design allows for biophilia; } \\
\text { appropriately ycaled for surrounding } \\
\text { ecological system. }\end{array}$ & $\begin{array}{l}\text { Biophilia is considered in most } \\
\text { asppects of design; rastores } \\
\text { impacted or degraded eocogical } \\
\text { syystems to their natural balance and } \\
\text { beauty. }\end{array}$ & 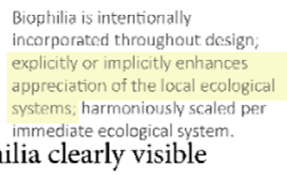 \\
\hline $\begin{array}{ll}\text { Era } & \begin{array}{l}\text { E.g. vehicles, } \\
\text { safety }\end{array} \\
\text { Distinctive period of history. }\end{array}$ & $\begin{array}{l}\text { Ignores consideration of current } \\
\text { era; blind to the concern of future } \\
\text { generations; serves initial purpose } \\
\text { only; efenericsolutions; premature } \\
\text { replacement occurs. }\end{array}$ & $\begin{array}{l}\text { Only attemplts trendy and } \\
\text { temmorarily satisfying solutions; } \\
\text { decisions made with only limited } \\
\text { exploration afalling back on status } \\
\text { quo or habitual solutions; outdated } \\
\text { quickly. }\end{array}$ & 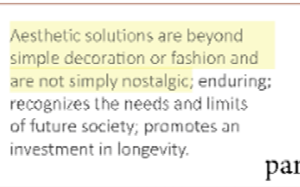 & $\begin{array}{l}\text { Encourages adaptability to alternate } \\
\text { uses; benefits future generations } \\
\text { of use solutions create authentic } \\
\text { sentimentality; honors the spirit or } \\
\text { the time. } \\
\text {, especially for tourism }\end{array}$ & 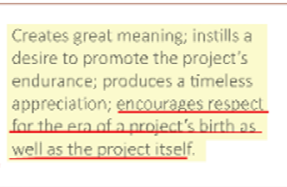 \\
\hline $\begin{array}{l}\text { Emotion \& } \\
\text { Sensory } \\
\text { Heighten feeling; relating to } \\
\text { sensation. }\end{array}$ & $\begin{array}{l}\text { Causes fear, repulsion or general } \\
\text { discomfort; breaks down the } \\
\text { spirit of the occupants; hopeless, } \\
\text { dangerous and/or unappealing } \\
\text { environments. }\end{array}$ & $\begin{array}{l}\text { Evokes limited or undesirable } \\
\text { emotions; causes boredom and } \\
\text { complacency; limited sensorial } \\
\text { displeasure. }\end{array}$ & $\begin{array}{l}\text { Creates a state of contentment and } \\
\text { peacefuluness; evokes feelings of } \\
\text { safery and satisfaction, responds to } \\
\text { humans love for nature and order. }\end{array}$ & $\begin{array}{l}\text { Encourages joy, energy, refection. } \\
\text { thought and productivity, enhaldes } \\
\text { well-being. } \\
\text { user-builder } \\
\text { perspective }\end{array}$ & $\begin{array}{l}\text { Evokes delight, happiness, } \\
\text { inspiratlon, deep reflection, great } \\
\text { achievement, appreciation or } \\
\text { Serenity; ;enerertes healing and self- } \\
\text { actualization; celebrates spirit. }\end{array}$ \\
\hline
\end{tabular}

Figure 2. Of the three lenses provided, (a) the vitality lens and (c) the foundations lens, were not used, while (b) the flows lens was used in conjunction with (e) the living environments in natural, social, and economic systems (LENSES) Rubrics. A new diagram (d) was formed of flow segments to present the results. 
The basics of the LENSES Rubrics evaluation process in this study are the two aforementioned research expeditions conducted by the first author. The selection of relevant flows as well as the evaluations of the focal points are based on seven semi-structured grounded interviews and on personal observations, as mentioned in [5]. Due to the highly specific context, the interviews cannot be published without compromising the interviewees' identities. The evaluation was conducted by a landscape architect specializing in Regenerative Design (Author 2, see [38]), an architect specialized in Living Architecture (Author 4, see [39]), and a civil engineer specialized in structural aspects of LRBs (Author 1 , see [5]) and supported later by an architect and researcher specialized in LRB ecosystem conservation and development (Author 3, see [7]).

\subsection{Selected Flows}

Of the 11 flows provided by CLEAR [34], seven were found to be relevant, namely Beauty, Community, Ecosystems, Education, Health and Wellbeing, Land Use, and Materials. Each of these flows holds within it between two and four focal points. The four flows Energy, Money, Transportation, and Water were excluded. The Rubrics charts approach these flows from a perspective irrelevant to LRBs. Water and Energy are approached from the point of view of a contemporary (e.g., residential) building, assuming a demand for these resources to fulfil the daily needs of the users. A bridge does not consume energy or water in the conventional sense (energy for heating and cooling or water for washing and cooking. Nonetheless, water is clearly relevant to LRBs since monsoon rainfall, humidity, and soil moisture are important parameters. These aspects are covered in other flows (for example, flooding is addressed in the Ecosystems flow). Transportation is understood in the Rubrics charts from an urban perspective, for example inspecting public transport availability. In a remote forest location with, in many cases, almost no modern forms of transport present, these arguments are not applicable. A similar situation occurs in the flow Money. While money from the tourist industry has a major influence on some bridges/communities, the worksheet appears inadequate for a full evaluation of a system that traditionally has no direct financial element.

LENSES encourages users to form new flows, two of which were made here: Governance and Time and History. Time and History is an important aspect of an approach that entails multigenerational efforts and long term growth processes. Governance structures underpin the shared responsibility for communal, long-term projects. Within these new flows, focal points were developed and evaluated, comparable to the standard Rubrics charts. The resulting worksheets are presented in the supplementary information. Within some of the provided flows, some focal points were added or taken away where necessary. This results in a total of nine flows made up of 27 focal points, five of which were added by the authors. Focal point selection is detailed and explained in Section 3.2.

\section{Results}

\subsection{Overview of Results}

Figure 3 shows the complete results of the Rubric analysis by focal points, arranged in flows. Flows that seem to have strong interdependences are arranged next to each other (e.g., Ecosystems and Land Use). Of the 27 focal points analyzed, 11 were found to be unambiguous (10 regenerative, 1 sustainable). Sixteen were ambiguous (relevant statements were found in more than one Rubric category). Of these, 3 were generally regenerative, 1 was regenerative/sustainable, and 12 had aspects ranging from regenerative to degenerative. While no entire flow was unambiguously regenerative, Land Use, Ecosystems, and Education showed only minor variations. Only Usability in Time (Time and History flow) and Opportunities for Change (Governance flow) were degenerative. Diversity (Ecosystems flow) and Relationships (Education flow) were sustainable. Below is a breakdown of the results by focal point. In Section 3.2, the assessments of individual flows are detailed for each focal point. 


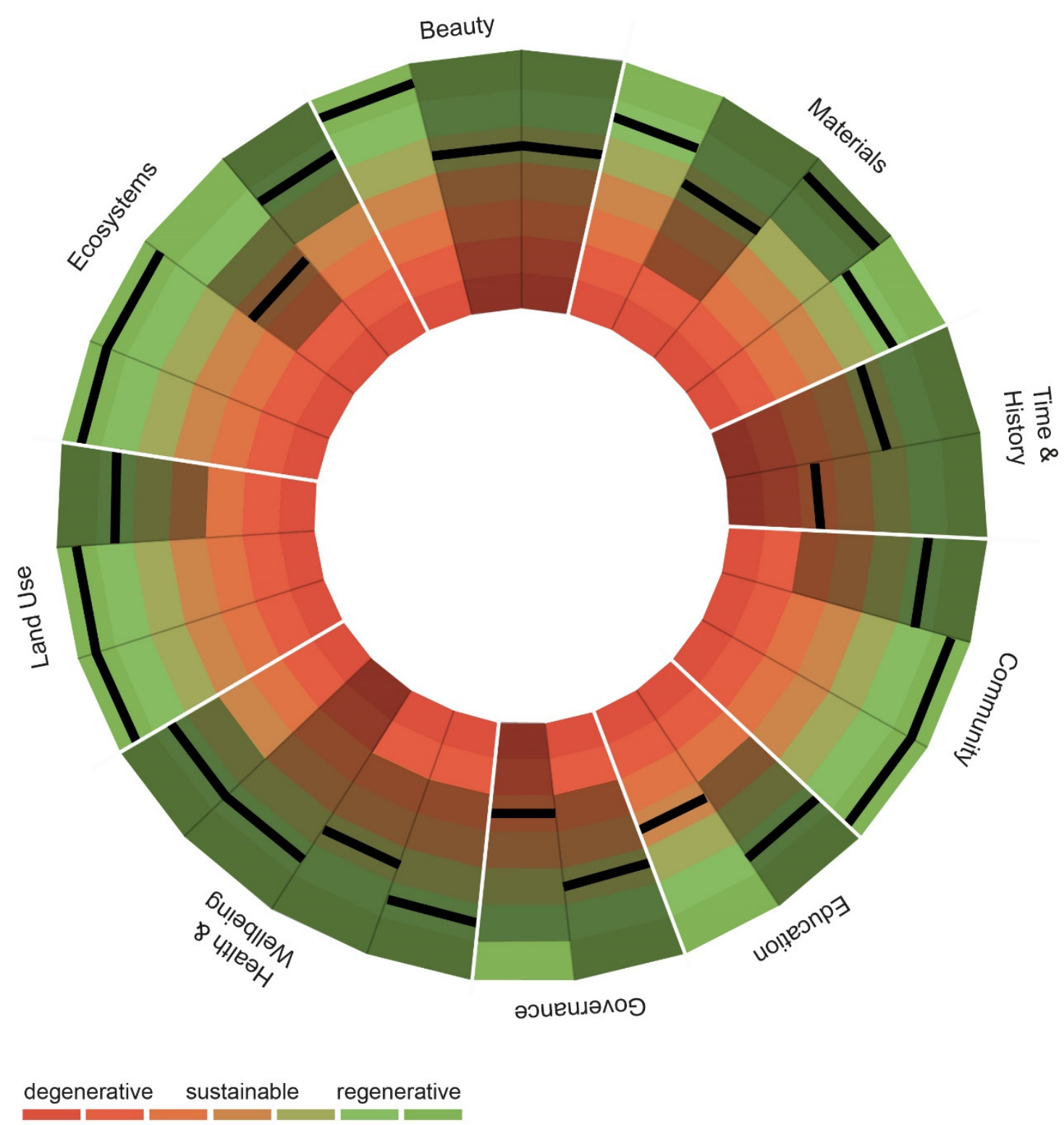

Figure 3. Summative circular presentation of the Rubrics evaluation based on the flows lens.

\subsection{LENSES Rubrics Evaluation Results}

\subsubsection{Beauty}

Three focal points are considered (shown in Figure 4): Ecological Beauty, which refers to the aesthetic expression of coherence within ecosystems (and the associated biophilia); Era, which relates to the balance between modernizing and traditional aesthetics; and Emotional and Sensory Beauty, which describes feelings and sensations when using the bridge. The first two focal points are mainly visual judgements, while the third includes considerations of the other senses. 


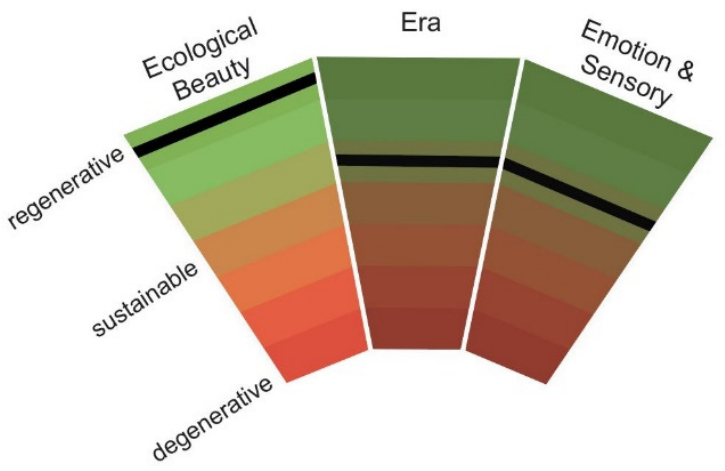

Figure 4. Evaluation results of the Beauty flow and its focal points.

\section{- Ecological Beauty: Clearly Regenerative}

Biophilic characteristics are clearly visible in LRBs (Figure 5b). All key LRB building materials arise from the local ecosystem, naturally supporting the growth of epiphytes and other flora and fauna (Figure 8a), forming pristine natural sites of ecological beauty. In doing so, LRBs "explicitly or implicitly enhance appreciation of local ecological systems". Three of the bridges documented in [5] that have become tourist hotspots rely on imported materials to improve accessibility (mostly concrete and steel). This negatively effects the ecological beauty of the place. Since this use of imported materials relates mainly to access paths and not within the bridges themselves and is an extremely recent phenomenon (in use for not more than 10-20 years), this aspect was not considered in the present evaluation (see Table 1 and discussion).
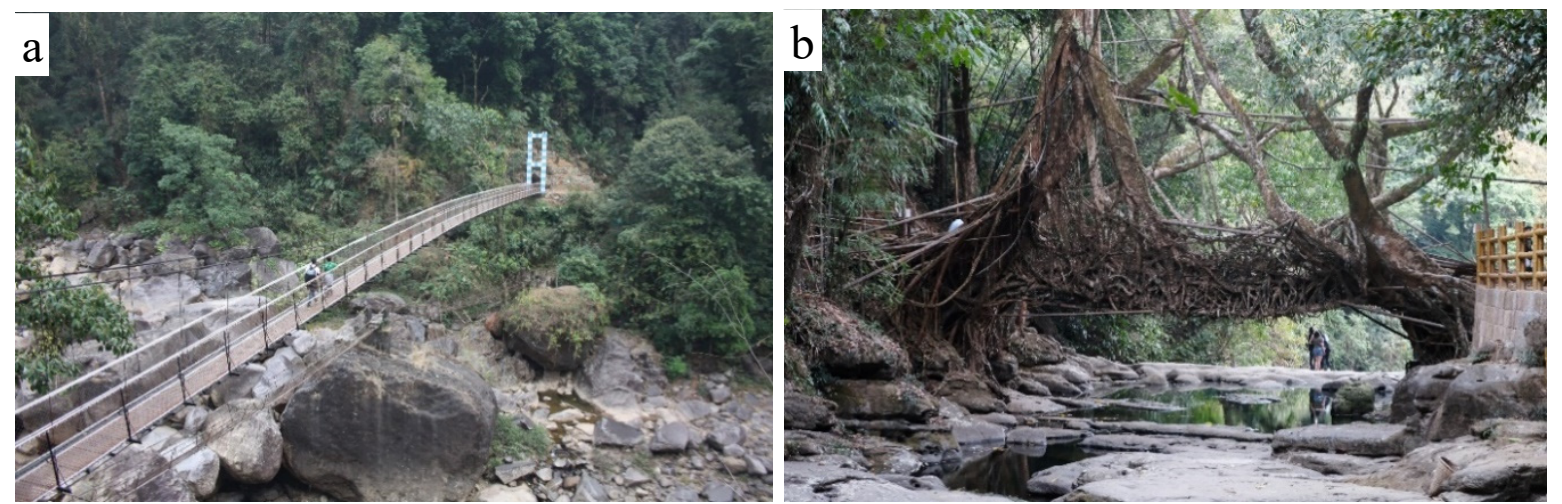

Figure 5. Two contrasting aesthetics: (a) The steel bridge towards Nongriat village can be described as modern, efficient, and professional; (b) the traditional Wah Thyllong bridge can be seen as an example of the Ecological Beauty of living root bridges (LRBs). The bank reinforcement and railing made of imported Cherra stone and painted reinforced concrete (imitating bamboo) illustrate a break with this tradition.

- Era: Contradictory, regenerative aspects predominate, degenerative aspects are present

LRBs are deeply ingrained in local traditions, which holds an aesthetic value. In the Rubric's terms, this "encourages respect for the era of (the) project's birth" and "produces a timeless appreciation". In Meghalaya, the discourse around environmentalism is developing and embodied by LRBs, a discourse that "promotes the project's endurance". However, the bridges rarely benefit from contemporary materials or technologies and lack "consideration of current era" and do not entirely "honor the spirit of the time", contrasting with the steel bridges built around Meghalaya, which have a grand, modern aesthetic (see Figure 5a). An ongoing discussion around sustainability could give LRBs more relevance in the current era. Contemporary materials are occasionally integrated into LRBs-steel wires and 
concrete sections can support weak bridges, though these are rare; in total, the authors have noted eight bridges with concrete or steel parts integrated for accessibility reasons and two for structural reasons. Three of these are due to an influx of tourists (see above), the other seven are to help a young or failing bridge. The technologies of the current era are also not considered, since LRBs are not used by (and have never been designed for) vehicular traffic and are not covered by contemporary building standards.

- Emotion and Sensory: Clearly regenerative with minor sustainable and degenerative aspects

There are some clear emotional and sensory drawbacks to LRBs. Especially to tourists and non-locals, some bridges can appear as quite unsafe structures (particularly when not well kept or crossing deep canyons), thus LRBs can "cause fear [and] general discomfort" and indeed are sometimes perceived as a "dangerous environment". Regarding this, it has to be added that steel and concrete bridges without due maintenance can cause the same fear-in fact, many such examples exist in the region. Aside from this, LRBs can "create a state of contentment and peacefulness", "respond to human love for nature", and evoke senses of "reflection", "achievement", and "serenity".

\subsubsection{Community}

The three focal points of the Community flow (Figure 6) are concerned with understanding the impact a project will have on the people who use it.
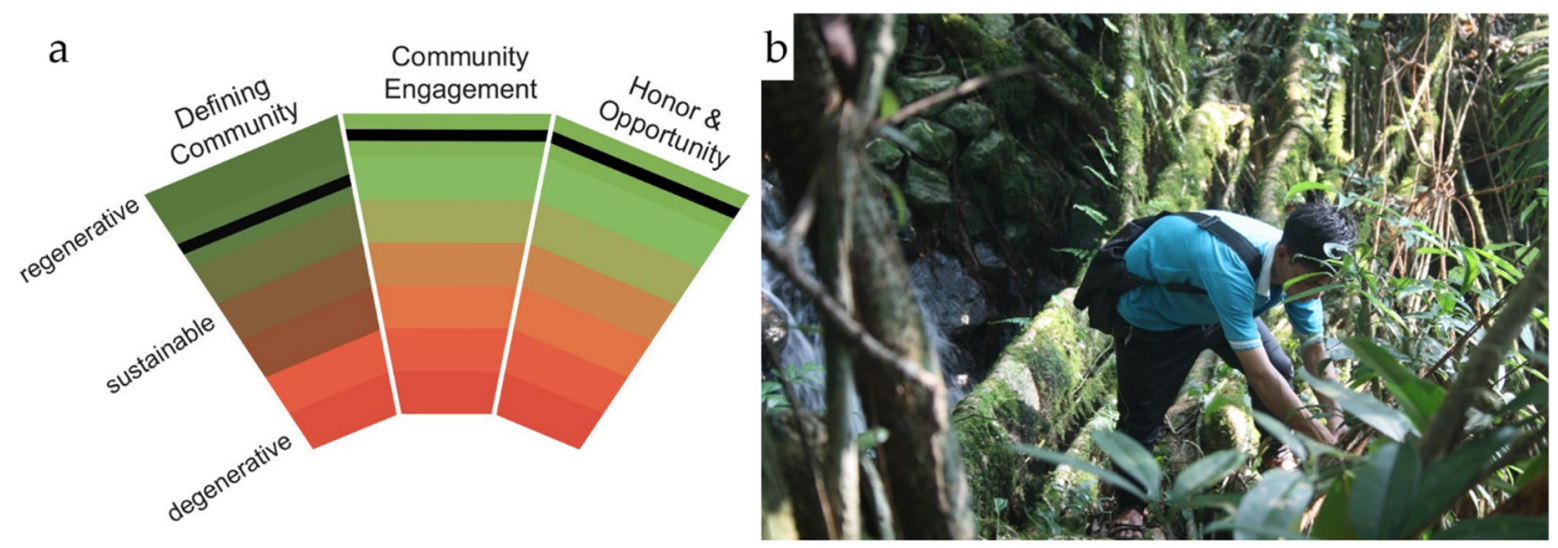

Figure 6. (a) Evaluation results of Community and its focal points; (b) a younger resident of Rangthylliang village engaging in LRB maintenance.

- Defining Community: Clearly regenerative with some slightly degenerative aspects

'Defining Community' can be described as a project's capacity to identify and integrate relevant stakeholders and their views. In traditional use, LRBs are often well integrated with their communities (a village, family, or consortium of villages) because of their essential maintenance requirements (typically a "user-upkeep" system, see Figure 6b). In fact, embedment in a user community is a precondition for LRBs to develop successfully because of the high time and effort investment in their construction and maintenance. As Shankar (2015) puts it, periodic maintenance "ensures a continual relationship between the living bridge and the local community" [7]. In some cases, new growth has been seen to reduce as a bridge ages, requiring reduced maintenance in root guidance. Their construction typically requires no money to buy externally sourced materials or external expertise. Most users have input into the maintenance regime, and thus "stakeholders are ... an accurate representation of the community". Though this representation is inherent to the LRBs' construction, it can be undermined by biased community governance structures. The recent exploitation of LRBs by the tourist industry usually involves a small, "self-selected" stakeholder group. Those who speak 
English or have access to technologies and social connections can benefit, often without generating positive "impact on the [wider] community".

- Community Engagement: Clearly regenerative

LRBs are inherently community projects, requiring good community engagement. The Rubric's rhetoric of bottom-up input does not entirely fit here. However, it is clear that they engage the community well through a variety of systems, which depend on local circumstances. As noted in Section 3.2.8, community participation can suffer when bridge- and landownership are in conflict.

- Honor and Opportunity: Clearly regenerative

Honor and Opportunity is concerned with an "understanding of local culture" and "creating opportunities through ... inclusive decision making". The user-upkeep model engenders "responsibility among community members" and uses an "iterative decision-making model".

\subsubsection{Ecosystems}

The four focal points defined by the Ecosystems Rubric (shown in Figure 7) apply well to LRBs. These are: Compatibility, through which plant, animal, and human communities support and reinforce one another; Productivity, which relates to the renewal of 'natural capital stocks' for ecosystem service provision; Diversity of species and populations; and Adaptability, understood here as the ability of a species, population, community and/or ecosystem to withstand and recover from internally or externally imposed changes or stresses.

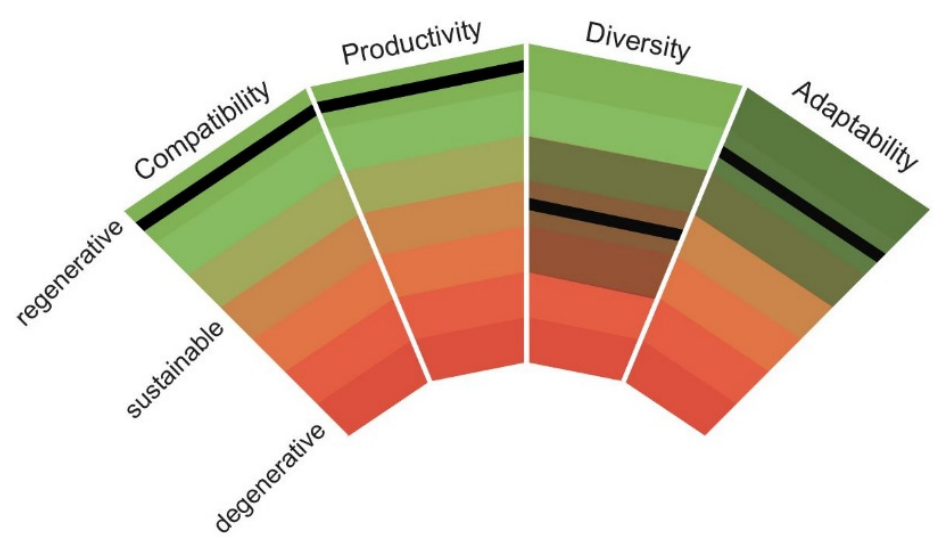

Figure 7. Evaluation results of the Ecosystems flow and its focal points.

- Compatibility: Clearly regenerative

The focal point Compatibility describes a regenerative project as allowing "plant, animal and human communities to renew and revitalize their own sources of energy". Energy is not as immediately important in LRBs as in other projects since the only direct energy inputs are through manual labor and sunlight (see materials and methods). By replacing "energy" with "materials" (the end result of energy input in many construction projects), it is clear that the bridges can be described as fully regenerative, especially because they also "enhance the interconnectedness and interdependence of systems, allowing the ecosystem to thrive".

- Productivity: Clearly regenerative

By providing villagers with access to remote farmland (that other bridge types cannot access), an LRB "actively promotes and manages capital stock". Thereby, they also are "catalysts for a healthy society and productive economic system" and therefore can be described as highly regenerative. 
- Diversity: Sustainable with some regenerative and potentially degenerative aspects

By planting F. elastica, bridge builders are using a potentially native tree $[5,40]$ that is described as a keystone species [41]. From this point of view, it can be stated that they "bring new life and vitality to an area" (regenerative). However, since this often happens within forests of high biodiversity [42] with many F. elastica specimens, it can also be stated that LRBs help to "preserve existing diversity" (sustainable). These conflicting perspectives are thus influenced by highly localized conditions. Additionally, the maintenance process can reduce biodiversity through the removal of plants growing on the bridges (see Figure 8a). Since this is as a purely manual (not chemical) process and a common practice in a managed forest used for agro-forestry, it is not seen as degenerative here. Localized ecological studies are required for a more fundamental understanding of the biodiversity impact of LRBs.
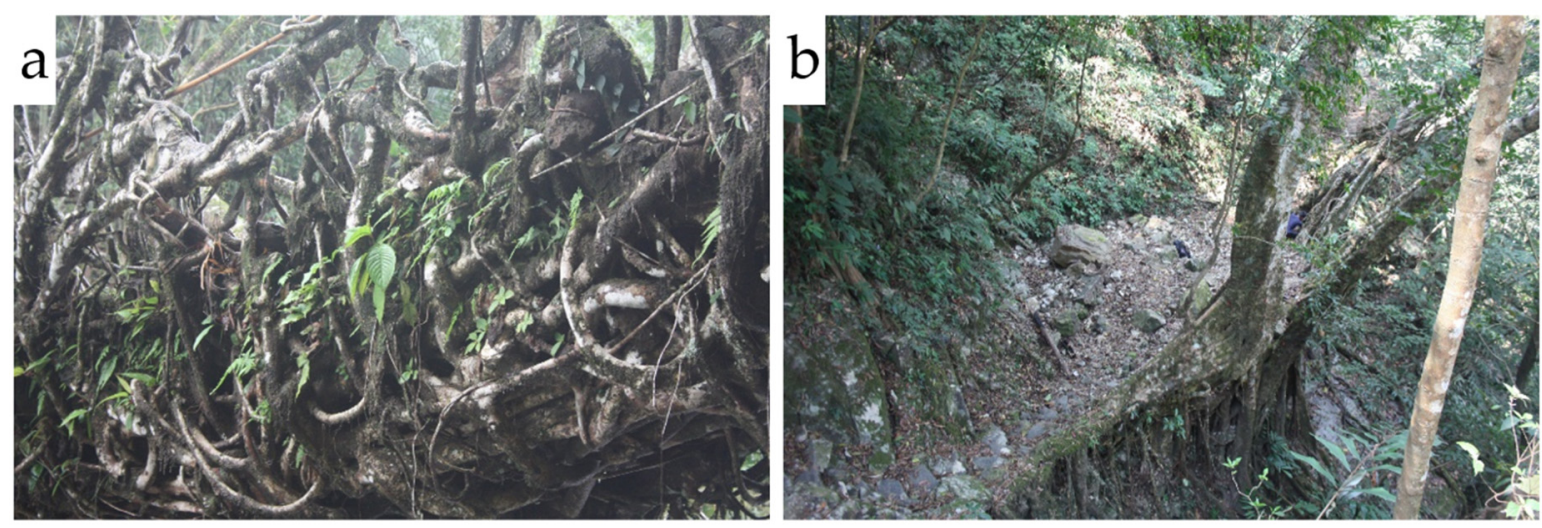

Figure 8. (a) Epiphytes are regularly cleaned from Wah Thyllong bridge, possibly inhibiting local ecosystem diversity. However, LRBs can also help ecosystems adapt to changes: (b) The parent tree of a bridge below Mawlam village held back a landslide (possibly caused by deforestation).

- Adaptability: Mainly regenerative

As integral parts of local ecosystems, LRBs express high adaptability especially through their potential to recover after being damaged by, for example, landslides or floods. By stabilizing the soil with their root system, they can even protect hillsides from landslides (see Figure 8b). In doing so, they "improve ecological resilience, making ecosystems able to adjust to most environmental changes". By providing access to productive forests, LRBs "support the sustainable harvest of a variety of renewable resources". As in all ecosystems, their adaptability is limited to a certain degree. Members of bridge-building communities report bridges destroyed by flash floods and by fire-an environmental impact that seems to put them at particular risk especially during the dry season. Altogether, it can be stated that LRBs show a high adaptability to some but not all relevant environmental factors.

\subsubsection{Education}

As the bridges are not grown with an explicit educational purpose in mind, two of the Rubric's focal points (Learning Space and Outcomes) were excluded here. Information and Skills Transfer and Relationships are considered (shown in Figure 9). 


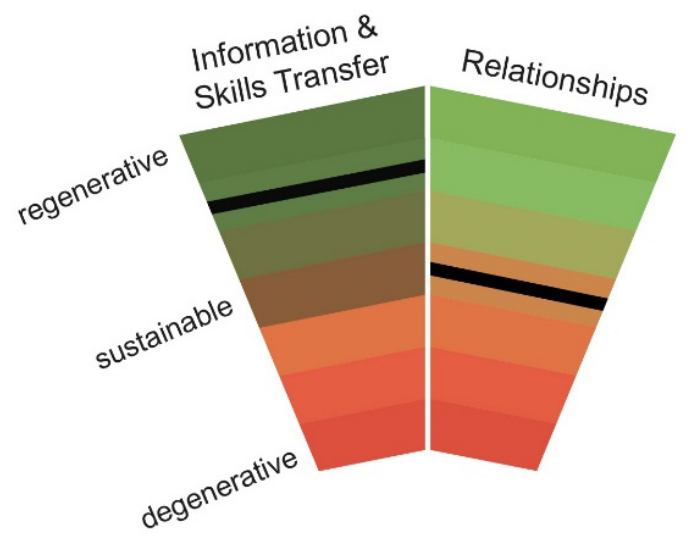

Figure 9. Evaluation results for the Education flow and its two considered focal points.

- Information and Skills Transfer: Regenerative as well as sustainable aspects

LRB growth techniques are passed down over generations within small, rural communities, often directly from parent to child. The transfer of these skills is extremely "hands-on" and "interactive". However, conflicts between villages have resulted in several cases of neighboring villages not sharing techniques. Furthermore, there is no formal system for knowledge transfer, which may be inhibitive.

- Relationships: Sustainable

Personal, organizational, and community relationships vary between villages. Bridge ownership, maintenance, and use structures come in many forms, from village consortia to individual village ownership, to smaller groups, and even private ownership. Within these structures, bridge building and maintenance is a deeply collaborative project, and "trust between players creates opportunities for communication and learning". However, some examples show that this inherent collaboration can quickly break down if a bridge is owned by only some of its users.

\subsubsection{Health and Wellbeing}

The Health and Wellbeing Rubric provides three focal points: Physical, Mental and Spiritual Balance, Equity and Inclusivity, and Healthy Lifestyles. As LRBs are first and foremost outdoor green infrastructures, a fourth focal point was added: Outdoor Comfort and Microclimate (Figure 10).

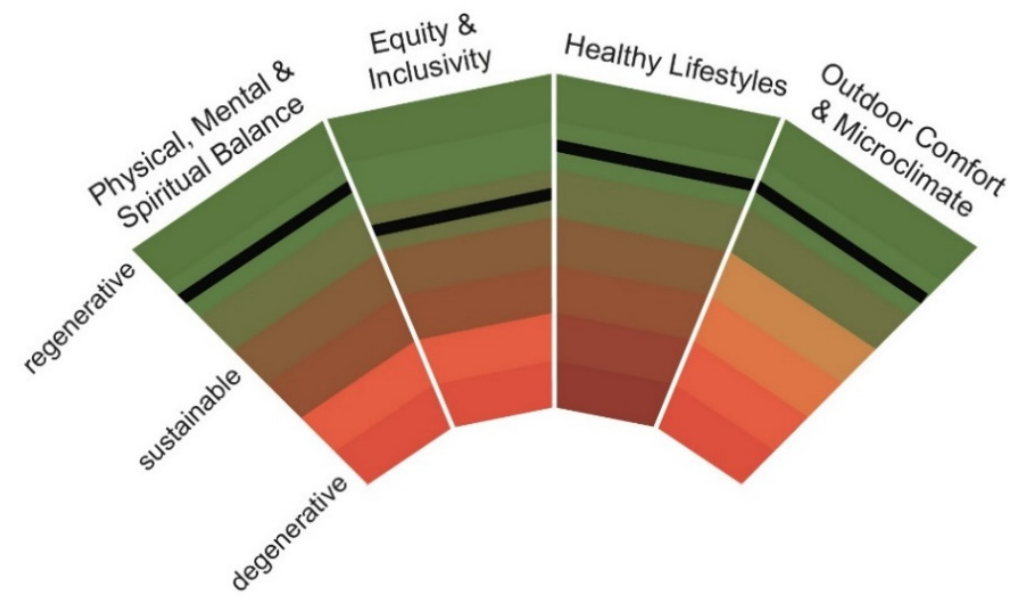

Figure 10. Evaluation results for the Health and Wellbeing flow and its focal points.

- $\quad$ Physical, Mental, and Spiritual Balance: Regenerative with degenerative aspects 
While the "interaction with nature" afforded by LRBs "nurtures ... spiritual health and well-being", they are inherently "not easily accessible for most populations", especially disabled or elderly. Here, in particular, the contrast between different perspectives (as mentioned in the methods section) prominently effects the evaluation results. LRBs are inaccessible, for example, by wheelchairs-a technical device not typically used in rural Khasi villages. Elderly Khasi and Jaintia people are well adapted to the steep topography and can access the bridges more easily. Furthermore, Khasi and Jaintia communities use woven bamboo carriages (on display at the Ever Living Museum, Shillong) to carry disabled people through the landscape and over the bridges. Thus, the physical, mental, and spiritual balance of LRBs is considered regenerative, though disadvantages must be taken into account.

- Equity and Inclusivity: Contradictory with regenerative and degenerative aspects

LRBs are, on the one hand, inclusive of "all ages ... and income levels" and on the other hand, can be exclusive of the disabled and elderly, particularly of tourists. Thereby they "discourage equal access and diversity." Some efforts have been made to make bridges more accessible in tourist hotspots, but their very rural locations limit the effectiveness of these measures. Some bridges have become more accessible due to the recent expansion of the rural road network in Meghalaya [43]. "Cultural, intergenerational, and biological diversity" are promoted within certain limits, with little possibility to integrate external influences.

- Healthy Lifestyles: Contradictory, strongly regenerative, but also highly degenerative aspects

LRBs do "create opportunities to heighten healthy lifestyles" by promoting physical exercise (particularly for visiting tourists) and "provide opportunities for social interaction ... natural light and interactions with nature". However, they are not subject to contemporary safety standards and their load-bearing capacity is not proven using contemporary methods. Therefore, LRBs in their early growth stages or when fallen into disrepair can be unsafe "space[s] for physical exercise", particularly for non-accustomed users (compare the role of user perspectives in methods section and discussion, also see Table 1 for a list of bridges used by tourists).

- Outdoor Comfort and Microclimate: Somewhat regenerative

Concerning outdoor comfort, some bridges provide shading (from the tree's canopy) in an otherwise exposed area above the river. Unlike, for example, the cables of steel bridges the natural material does not heat up in the sun which makes it comfortable to touch. However, they do not provide shelter from rain, which is torrential between May and August (though this is clearly not the main function of a bridge). In total, they do not negatively influence the microclimate of the rainforest and in some cases they benefit the microclimate by covering areas of otherwise bare riverbanks.

\subsubsection{Land Use}

LENSES Rubrics suggests three focal points for land use, namely Natural Land, Building Land, and Productive Land (shown in Figure 11). Due to their multifunctional character and because of being highly embedded in the ecosystem, a clear separation into these sub-categories is difficult here. To cope with these circumstances, the following assessment uses the proposed arguments only partially and argues more freely. 


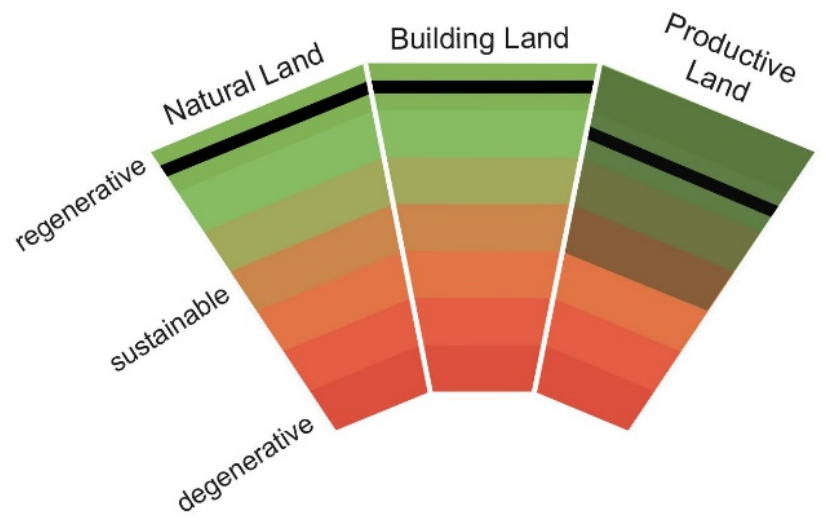

Figure 11. Evaluation results for the Land Use flow and its focal points.

- Natural Land: Highly regenerative

LRBs promote and support the functionality of natural land and provide habitats for native species. They are an integral part of the natural land use and therefore balance natural capital and human land use. Thus, they clearly show a high regenerative potential.

- Building Land: Highly regenerative

The Rubric focuses here on the interaction of a building with its local environment. As LRBs are grown directly from their environment, they can be considered as clearly regenerative (generating themselves). Traditionally, there is no production of waste and they do not release any pollutant on site. Aspects of local history are exhibited through the reliance on several (living and past) generations of builders-indeed, LRBs are testament of a community's long-term presence. As the bridges are entirely grown and maintained by their communities, they "empower local culture with development decisions".

- Productive Land: Regenerative with some contradictions

LRBs provide access to land that would be unreachable without them (especially during the rainy season). Thereby they enable productive use of land otherwise unused by humans and are integral parts of the agro-forestry system of the Khasi and Jaintia culture. Additionally, they offer a supply of latex used for hunting and waterproofing (Figure 13b), though over-extraction can kill the tree and destroy the bridge. Today, LRBs are becoming "productive" through tourism. This can benefit the communities economically but has clear side effects such as littering and water pollution and unclear long-term socio-economic effects.

\subsubsection{Materials}

The Materials flow is comprised of four focal points (Figure 12): Elegant Simplicity, whereby "no more causes or forces are used beyond being effective"; Health and Wellbeing, understood here as the holistic support of health, comfort, beauty, and social responsibility; Environment, considering the multiscale environmental impact of material selection; and Region, which judges the appropriate use of materials in terms of a place's history, culture, and sense of local identity. 


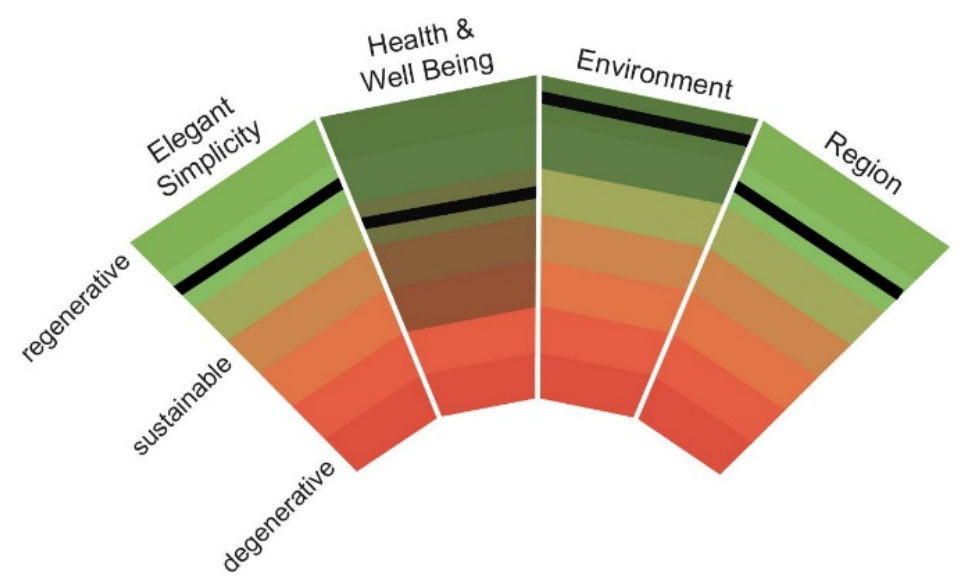

Figure 12. Evaluation results for the Materials flow and its focal points.

- Elegant Simplicity: Regenerative

Utilizing just one major material, the living wood of a native species, LRBs "dramatically reduce the use of materials". Bamboo and Areca catechu palms, often used in the early stages of growth, are abundant in the surrounding forest (Figure 13a,c). Apart from the flat stones, which are sometimes used to form the deck, all building materials are completely biodegradable, directly rejuvenating the local ecosystem. The recent use of steel, concrete, bricks, and paint on or nearby some bridges goes against this trend, though this is uncommon and unnecessary in well-maintained bridges.
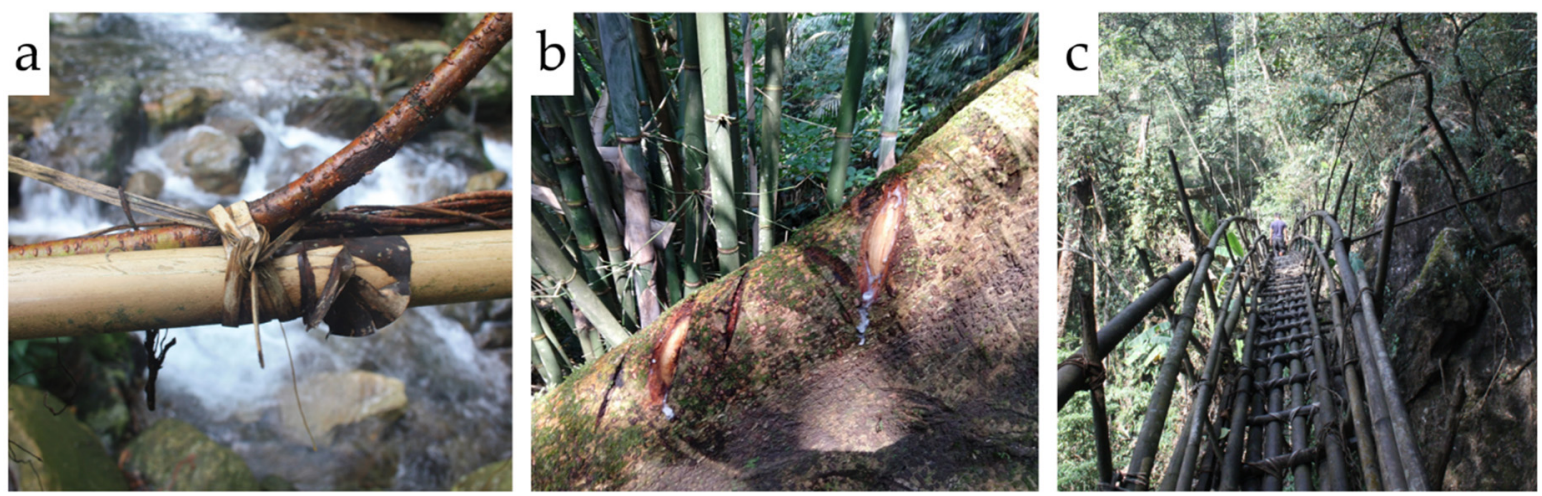

Figure 13. LRBs are traditionally made from materials available in the nearby forest: F. elastica aerial roots, bamboo, and Areca catechu palm trunks. (a) shows a guided root on a bamboo scaffold; (b) shows scars from latex extraction, used for waterproofing and hunting; (c) is a bridge in Rangthylliang village, which has been rebuilt following its destruction by fire (F. elastica is highly flammable).

- Health and Wellbeing: Contradictory with regenerative and degenerative aspects

LRBs provide, in the words of the Rubric, "inspirational aesthetics, celebrating beauty with a deep connection to nature" - which can clearly be considered regenerative. However, the latex-rich wood of F. elastica is prone to fire-several bridges have burnt down in living memory (Figure 13c).

- Environment: Highly regenerative

The material selection of LRBs is clearly environmentally regenerative, as it "eliminates materials and related processes that contribute to environmental degradation", apart from the recent and uncommon (but increasing) use of steel cables and concrete posts specifically in sites open to tourists. The production, import, use, and waste products of these materials can be detrimental to the local and wider environments. 
- Region: Highly regenerative

The bridges "minimize importation" of materials and "preserve heritage and cultural authenticity" by making use of traditional techniques in bamboo, areca palms, and F. elastica. This "prompts regional self-sufficiency and long-term economic health" as the farming and tourist industries benefit (from the local community's input) in the long term. The use of F. elastica is widespread in Khasi and Jaintia culture, and thus forms part of a wider regional identity. A sense of place is also clear, as the bridges are highly unique.

\subsubsection{Governance}

Governance in LRBs manifests mainly as decision-making in the maintenance process but also includes wider ranging decisions concerning present use and future development. Within governance structures, two focal points were identified: Proportional Voices, concerning the even distribution of decision-making between all stakeholders; and Opportunities for Change, describing the ease with which governance structures can adapt and react to changing conditions and challenges (Figure 14). Over the lifetime of a bridge (up to hundreds of years), relevant governance structures can change dramatically on all levels (e.g., village, municipality, region, and state level). Traditionally, LRBs mainly had a local economic and societal relevance (providing farm, village, and market access) and therefore have been governed on a local level. Three main systems of bridge ownership and maintenance conventionally dominate: A consortium of villages (raid), a single village (shnong), and an individual, family, or tribe (kur) [5,44]. These do not preclude land ownership-community land (ri raid) or private land ( $r i$ kynti-all translations taken from [44]). This can lead to conflicts between bridge- and landowners and thereby can influence community participation. With Meghalaya's special status under the Constitution of India and with the recent onset of tourism, LRBs are gaining wider recognition and regional governance structures are becoming more influential.

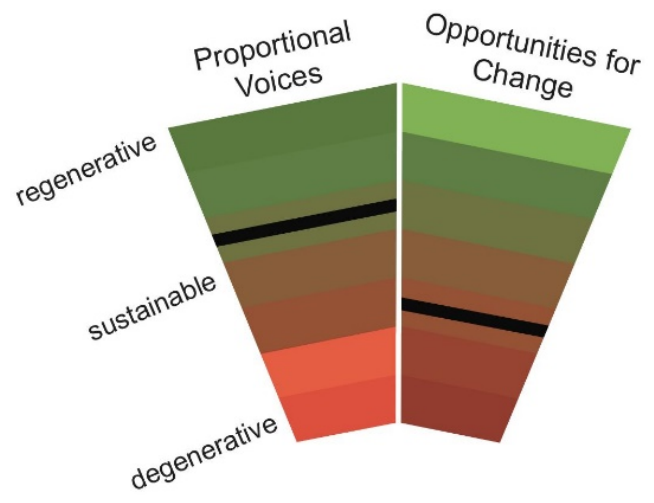

Figure 14. Evaluation results for the Governance flow and its focal points.

\section{- Proportional Voices: Regenerative with degenerative aspects}

The majority of maintenance decisions are made on the day-to-day basis, with users contributing to maintenance. Thus, decisions can be said to be built over "rounds of consultation" through the bridge growth process, giving all users the opportunity to contribute. Additionally, there are larger decisions like adding reinforcements, replacing a bridge, changing the accessibility, or charging tourists to visit, that are in the end made by the owners or regional authorities, which is not an inherently proportional system. At the village level, some representational structures exist such as village committees led by the village headman. The election of the headman varies between villages and the process is not standardized across the region. However, most user communities are small enough to allow shared agreement that represents the majority of stakeholders.

An important issue in regenerative design and development is to take an intergenerational perspective, taking into account the voices of children and descendants, often a minority or even 
unrepresented voice. With their long growth periods, LRBs are inherently aimed at providing a service for future users and thereby provide an excellent example for giving future generations a voice.

- Opportunities for Change: Contradictory with degenerative aspects dominating

Like a lot of traditional communities around the world, many Khasi and Jaintia communities are witnessing fundamental societal change. In the context of economic development, roads and other technical infrastructures are built throughout the region often by the state or autonomous regional government. Increased formal education and opportunities has led to greater numbers of young people leaving the villages. At the same time, well-preserved natural heritage and especially the LRBs have, in recent years, attracted growing numbers of tourists, which has had a fundamental social and economic impact. The traditional governance structures for LRBs in Meghalaya obviously are not built to cope with these changes.

Community governance structures regarding the bridges differ between villages and are not well coordinated. Therefore, their ability to engage with regional and supra-regional changes is quite limited. In some cases, the literate younger generation clearly sees the opportunities and challenges coming with tourism and may have more adequate skills to deal with them. However, the village headman system very often empowers the elderly (of certain families) who may be less able to deal with tourism due to language and entrepreneurial requirements. In recent years, a number of entrepreneurial groups (some are notably intergenerational) have emerged to overcome these barriers. The focus of these initiatives is on eco-tourism making use of LRBs as local heritage and engaging young people in maintaining and building new LRBs. Such shifts can lead to intergenerational conflicts over ownership.

In summary, this shows that there are some opportunities for change in governance but the traditional system in power today has some limitations. At the same time, the new initiatives only represent a minority within concerned communities.

\subsubsection{Time and History}

Two focal points were developed within Time and History: Historical Narrative, which balances the community's traditional and progressive values to form a coherent story, and Usability in Time, which understands the yield of the project over its lifetime. Both focal points are shown in Figure 15.

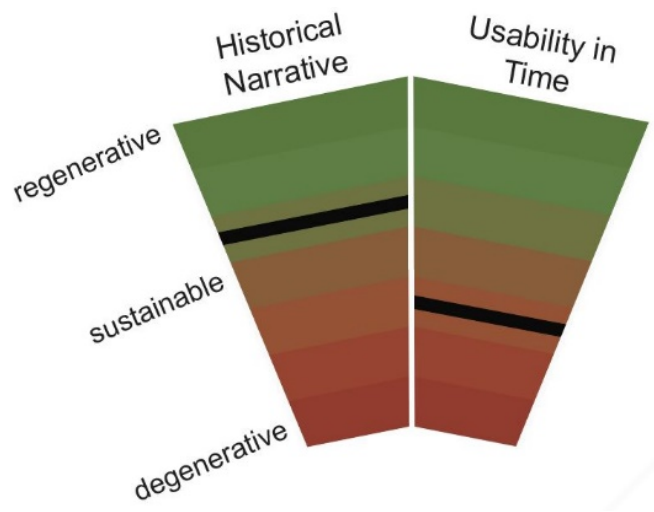

Figure 15. Evaluation results for the Time and History flow and its focal points.

- Historical Narrative: Contradictory with degenerative and regenerative aspects

While LRBs form a major part of traditional village narratives and thus "integrate community history and environment", they make a mixed contribution to a progressive narrative. As described above, many remote areas of the Khasi and Jaintia Hills have been recently linked to the outside world and discovered the benefits of contemporary technologies, including steel and concrete bridges, which are thought to be strong, safe, and easily built. In reality, numerous concrete and steel bridges are in poor condition and unmaintained. They can degrade quickly and become unsafe. Nonetheless, LRBs 
are seen as technically outmoded, representing an admirable history but not a future development solution. This causes a strong disruption in the narrative. On the other hand, protecting the environment is valued both traditionally and in contemporary society. In this context, LRBs are seen as a form of architecture, which sets an example for future development and contributes to a progressive narrative.

- Usability in Time: Mixed regenerative and degenerative aspects

Since LRBs require many years to grow into a stable structure, they cannot be used in the short-term, rather only in the long-term. Bridge builders traditionally try to overcome this delay by making the temporary bamboo scaffolding accessible (see Figure 13c). Despite a very quick construction, maintenance is time consuming as the bamboo rots quickly and has to be replaced every few years. However, once established, LRBs can be extended in use, growing stronger and safer with time. Several older bridges have wider, flatter gangways that can be used by a wider range of people (Figure 16a). Others show secondary decks, which have been grown to accommodate additional (pedestrian) traffic or in order to have uninterrupted use of the bridge during floods (Figure 16b).
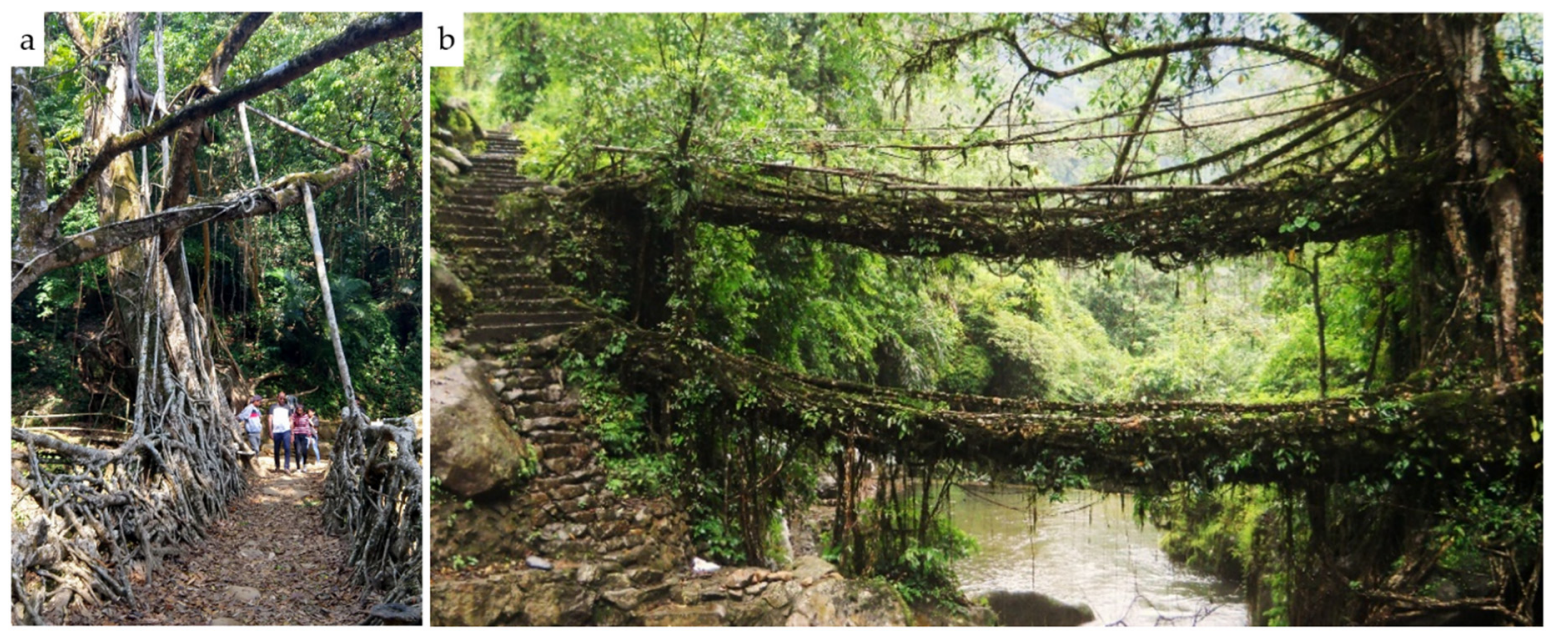

Figure 16. (a) Wah Thyllong bridge connecting Nohwet and Riwai villages has a wide and comfortable gangway. (b) A second deck was established on Nongriat Double Decker bridge. According to local residents, the upper deck was grown to allow the use of the bridge when the lower deck was flooded (photo: Patrick Rogers).

\section{Discussion}

In the following, we discuss the benefits and drawbacks of LENSES as a tool to analyze LRBs on the DSR spectrum. Furthermore, we provide the broader context in which this study lies and discuss future research directions.

\subsection{Suitability of LENSES Rubrics for This Study}

Qualitative tools such as LENSES Rubrics deliver results based on the subjective assessment of the authors and can therefore only be generalized to a limited extent. Through the intensive discussion of all individual aspects between the authors, who view LRBs from very different cultural and disciplinary contexts, an attempt was made to obtain a holistic assessment. One benefit of this multifaceted focal-point analysis is that the impact of judgement errors (due to potential knowledge gaps) is reduced. The increased detail led to some overlap of specific focal points and flows (e.g., Health and Wellbeing as a flow and also as a focal point in the flow 'Materials'). Some redundancy is caused but approaching each aspect from multiple angles led to new insights relevant to a complete understanding.

The structure of flows and focal points proposed by CLEAR led to the result that highly relevant aspects, such as safety, only appear as partial aspects of different focal points; integrated throughout 
the framework, not explicitly expressed. Safety is quite degenerative in LRBs, but the focal points in which it appears are only found to be contradictory overall, which could mislead users. A conflict clearly arises here between contemporary notions of safety as the highest and first priority of built projects and the holism of the LENSES framework. A second round of assessment could integrate a single focal point or flow, named 'Safety and Reliability', which might go some way to solving this.

Another challenge in the application of LENSES Rubrics was that the tool is clearly developed for projects in a more urban context and thus for at least partially degenerated ecological conditions and extremely different social conditions. As shown in the methods section, the authors reacted to this by selecting only the most appropriate flows and introducing new ones. Nevertheless, in the case of Biodiversity, for example, the problem arose that LRBs cannot make a major contribution to increasing biodiversity in a forest area of already high biodiversity and were therefore not classified as clearly regenerative. In a biologically degraded or heavily built-up context, this would be quite different. It is important to reiterate that the traditional worldview of rural Khasi communities includes non-mechanistic, holistic themes, resonating well with the regenerative approach [11,12].

\subsection{Discussion of Comparable Methodological Approaches}

This study applies a practitioners' tool (LENSES Rubrics) that has arisen from the academic literature of regenerative development and design [31-33]. While regeneration, regrowth, and renewal are the defining features and key terms of the regenerative paradigm, there are many examples of tools within the wider sustainability literature that enable regeneration without explicitly naming it. Regenerative themes (e.g., biophilia, system harmony) are often present. Two such approaches are briefly presented here to discuss the present study in a broader academic context.

Sharma [45] discusses city greening methods with respect to 'landscape synergism'. They focus on an urban greening technique called "greenways" that utilizes existing (often blue/green) linear areas as multifunctional landscape features. This approach aims to create synergies by minimizing changes to functioning ecosystems while embedding human systems. For example, streams through urban areas form the basis of cycle and pedestrian routes [46,47]. As synergistic co-existence of social and ecological functions, LRBs are genuine examples of landscape synergism. The systems-oriented framework of landscape synergism provides a strong link between design and analysis. Thus, integration of regenerative and landscape synergism approaches could provide a structure for holistic, design-applicable analysis that helps foresee and avoid potential degenerative side effects.

Ecological land-use complementation (ELC) is a framework through which planners promote biodiversity through land use combinations [48]. In effect, this builds on known regenerative aspects of a landscape, with a focus on ecology. This approach aims to promote resilient systems, a key feature of regenerative design. Design tools such as ELC may be useful in combination with the multi-flow view provided in a LENSES Rubrics analysis in order to integrate multifunctionality in a holistic approach beyond ecology. The conceptual framework developed by Hansen and Pauleit [49] for multifunctionality in green infrastructure planning points in this direction.

LENSES Rubrics have been used here to describe LRBs as a vernacular form of living architecture in their current context. So far, tools for regenerative design and development have not been applied to adapt vernacular systems to a modernizing context. Outside of the regenerative design movement, examples of comparable transition processes can be found in the architectural practice. Anna Heringer's DESI training center, for example, demonstrates how vernacular technologies can be adapted to changing pressures by improving their strengths and overcoming their weaknesses. In this project, traditional clay building techniques have been further developed to create a modern type of building — a school—based on the knowledge and social networks of all involved stakeholders, underpinned by state-of-the-art design approaches [50,51]. A comparable approach is conceivable for LRBs.

In addition to such a local adaptation, our LENSES analysis can enable LRBs to become concept generators for regenerative design projects as well as modern forms of living architecture in different 
contexts. An example of such a transfer is permaculture, which makes vernacular forms of agriculture applicable in globalized societies [52]. Ferreira et al. [53] describe Sunspaces, a regenerative vernacular microclimatic technology, and discuss its extraction and utilization in contemporary architecture. In order to preserve the regenerative aspects in such transfers, a close consideration of the systems between which the technologies are transferred is essential. In this process, LENSES Rubrics can also be applied iteratively to assess the transfer's success.

\section{Conclusions}

The evaluation of LRBs with the LENSES Rubrics tool led to a significantly deeper understanding of the technological, ecological, and societal conditions under which they arise. The fact that most focal points were assessed as regenerative confirms the initial hypothesis. Nonetheless, degenerative aspects were identified. The partially inadequate safety and limited reliability in early years of growth are particularly clear degenerative aspects, which became apparent in a number of focal points. The questions raised in the LENSES Rubrics worksheets contributed significantly to identifying these points. These findings provide a good basis for possible future attempts to overcome current economic, social, and environmental pressures on LRBs. While LRBs have so far been used almost exclusively by the local population to reach fields, markets, and neighboring villages, they are currently being used increasingly by tourists or are themselves becoming a tourist attraction. Thus, while they are a potential source of income for the local population, the visit of several hundred tourists per day creates a usage pressure, which can significantly damage the bridges and the related ecosystems. Government, private, and non-profit initiatives are being developed to use and grow LRBs in the context of eco-tourism $[7,54,55]$. In this context, the present study reveals that the historically grown social structures face enormous challenges. The passing down of knowledge between generations is an essential traditional social structure for the bridges' future, but new challenges in a changing society require new structures, particularly in negotiating with parties from outside the community such as governments, tourists, and businesspeople. Safety and reliability must be improved for tourist use. The potential of contemporary innovative design and engineering tools to improve the safety, stability, ecosystem-services, and longevity of LRBs should be linked as synergistically as possible with traditional approaches (see the Baubotanik approach, discussed in [39]). In helping this transformation process, tools such as LENSES offer an adequate base but need to be adapted for specific conditions. With the inventory and assessment of the status quo, this study can offer a starting point for such a developmental process. Additionally, this study is a first attempt to analyze vernacular architecture systematically through regenerative design and development thinking, and as such goes some way to establishing a methodological basis for further studies and applications.

Supplementary Materials: The following are available online at http:/www.mdpi.com/2071-1050/12/8/3267/s1, Table S1: Nine Completed Rubrics Worksheets.

Author Contributions: The author contributions are as follows: Conceptualization, A.H., F.L., and W.M.; methodology, A.H., F.L., and W.M.; validation, S.S.; writing-original draft preparation, A.H., W.M., and F.L.; writing-review and editing, W.M., F.L., and S.S.; supervision, F.L.; funding acquisition, W.M. and F.L.; unless otherwise specified, photography by W.M. All authors have read and agreed to the published version of the manuscript.

Funding: The field expeditions carried out by W.M. central to this research were funded by the award for bold science (Preis für mutige Wissenschaft) by the Ministry of Science, Research and the Arts Baden-Württemberg (2017) and Technical University of Munich International Center (2018). The APC was funded by Technical University of Munich.

Acknowledgments: The authors would like to honor and thank the rightful owners of the Living Root Bridges-the indigenous Khasi and Jaintia communities. Without the intergenerational efforts of village communities Living Root Architecture and the inspiration it provides would not exist. The authors also thank all those who generously gave their time during the research surveys and helped during interviews: thanks go to all those involved in supporting, translating, and guiding W.M. and S.S. in Meghalaya, Pynbait Pahsyntiew, Pynhun Khongthohrem, and Byron Nongbri, as well as the people of Nongriat, Laitkynsew, Siej, Nowhet, Nongbareh, Mawlam, Shnongpdeng, Laitiam, Tynrong, Nongsteng, Kongthong, Mawshuit, Kudeng Rim, Rymmai, Rangthylliang, Urksew-Wahpathaw and Nongblai villages, and in particular the Rangthylliang Ecotourism Cooperative Society: Phlatsing Khongmawloh, 
Morningstar Khongthaw, Shiningstar Khongthaw, Wanbha Khongsdam and Pynhun Khongthohrem for their indefatigable efforts. Thanks to Lea Reiter for her technical support in visualizing the results. This work was supported by the German Research Foundation (DFG) and the Technical University of Munich within the funding program Open Access Publishing. We would like to acknowledge critical advice and support from National Geographic Society, Meghalaya Basin Development Authority, Government of Meghalaya, Khasi Hills Autonomous District Council, Jaintia Hills Autonomous District Council, North Eastern Hill University and all stakeholders who continue to engage in ongoing Living Root Bridge conservation, research and restoration efforts.

Conflicts of Interest: The authors declare no conflict of interest. The funders had no role in the design of the study; in the collection, analyses, or interpretation of data; in the writing of the manuscript, or in the decision to publish the results.

\section{References}

1. Nilaweera, N.; Nutalaya, P. Role of tree roots in slope stabilisation. Bull. Eng. Geol. Environ. 1999, 57, 337-342. [CrossRef]

2. Brundtland, G.H. Report of the World Commission on Environment and Development: "Our Common Future"; Oxford University Press: Oxford, UK, 1987.

3. Kubba, S. LEED v4 Practices, Certification, and Accreditation Handbook, 2nd ed.; Elsevier Butterworth-Heinemann: Oxford, UK, 2015. [CrossRef]

4. Yule, H. Notes on the Kasia Hills, and People. J. Asiat. Soc. Bengal 1844, 13, 612-615.

5. Ludwig, F.; Middleton, W.; Gallenmüller, F.; Rogers, P.; Speck, T. Living bridges using aerial roots of ficus elastica-an interdisciplinary perspective. Sci. Rep. 2019, 9, 1-11. [CrossRef] [PubMed]

6. Chaudhuri, P.; Bhattacharyya, S.; Samal, A.C. Living Root Bridge: A potential no cost eco-technology for mitigating rural communication problems. Int. J. Exp. Res. Rev. 2016, 5, 33-36.

7. Shankar, S. Living Root Bridges: State of knowledge, fundamental research and future application. IABSE Symp. Rep. Struct. Eng. Provid. Solut. Glob. Chall. 2015, 1, 1974-1981. [CrossRef]

8. Middleton, W.; Shu, Q.; Ludwig, F. Photogrammetry as a tool for living architecture. Int. Arch. Photogramm. Remote Sens. Spatial Inf. Sci. 2019, 42, 195-201. [CrossRef]

9. Bareh, H. The History and Culture of the Khasi People, 3rd ed.; Spectrum Publications: Guwahati, India, 1997.

10. Malngiang, P. Aspects of Khasi Philosophy, 1st ed.; Seven Huts Enterprise: Shillong, India, 1991.

11. Lyngdoh, S.S. Chapter 11 Modern developmental philosophy of nature and traditional Khasi ecology; thinking with Heidegger. In Environment-Cultural Interaction and the Tribes of North-East India; Mawlong, B.S., Mitri, M.B., Eds.; Cambridge Scholars Publishing: Newcastle-upon-Tyne, UK, 2015; p. 119.

12. Chakraborty, S. Khasi hills and Khasi culture: Reconnection in Kynpham Sing Nongkynrih's The Yearning of Seeds. J. Commonw. Lit. 2018, 53, 1-18. [CrossRef]

13. Sing Nongkynrih, K. The Yearning of Seeds; Harper Collins India: New Delhi, India, 2011.

14. Shangpliang, R.M. Forest in the Life of the Khasis; Concept Publishing Company: New Delhi, India, 2010.

15. Tiwari, B.; Tynsong, H.; Lynser, M. Forest management practices of the tribal people of Meghalaya, North-East India. J. Trop. For. Sci. 2010, 22, 329-342.

16. Cajee, L.; Lyngdoh Tmar, U.; Syiemlieh, H. Community participation in forest management in Meghalaya. NEHU J. 2010, 3, 89-98.

17. Tiwari, B.; Tripathi, R.; Barik, S. Sacred groves of Meghalaya. In Conserving the Sacred for Biodiversity Management, 1st ed.; Ramakrishnan, P.S., Saxena, K.G., Chandrashekara, U.M., Eds.; Science Pub. Inc.: Enfield, NH, USA, 2011.

18. Ormsby, A. Analysis of local attitudes toward the sacred groves of Meghalaya and Karnataka, India. Conserv. Soc. 2013, 11, 187-197. [CrossRef]

19. Roxburgh, W. Flora Indica: Or Descriptions of Indian Plants. Reprinted Literatim from Carey's Edition of 1832; Thacker, Spink: Calcutta, India, 1874.

20. Marcuse, P. Sustainability is Not Enough. In The Future of Sustainability; Keiner, M., Ed.; Springer: Dordrecht, The Netherlands, 2006; pp. 55-68.

21. Bartlett, A.A. Reflections on Sustainability, Population Growth, and the Environment-2006. In The Future of Sustainability; Keiner, M., Ed.; Springer: Dordrecht, The Netherlands, 2006; pp. 17-37. 
22. Hurley, J. Sustainable or status-quo: Investigating sustainability assessment of residential estate development. In Proceedings of the State of Australian Cities National Conference 2009, Perth, Australia, 24-27 November 2009.

23. Rosser, A.M.; Mainka, S.A. Overexploitation and species extinctions. Conserv. Boil. 2002, 16, 584-586. [CrossRef]

24. Lyle, J.T. Regenerative Design for Sustainable Development; John Wiley \& Sons: New York, NY, USA, 1996.

25. Mang, P.; Reed, B. Regenerative Development regenerative development and Design. In Encyclopedia of Sustainability Science and Technology, 1st ed.; Meyers, R.A., Ed.; Springer: New York, NY, USA, 2012; pp. 8855-8879.

26. Akturk, A. Regenerative Design and Development for a Sustainable Future: Definitions and Tool Evaluation; University of Minnesota Digital Conservancy: Minneapolis, MN, USA, 2016.

27. McHarg, I.L.; Mumford, L. Design with Nature, 1st ed.; Natural History Press: Garden City, NY, USA, 1969.

28. Mollison, B. Permaculture: A Designer's Manual, 1st ed.; Tagari Publications: Tyalgum, New South Wales, Australia, 1988.

29. Shankar, S. GroWorld-Urban Permaculture towards Symbiotic Relationships and Sustainable Futures; FoAM: Brussels, Belgium, 2008.

30. Cole, R.J. Regenerative design and development: Current theory and practice. Build. Res. Inf. 2012, 40, 1-6. [CrossRef]

31. Plaut, J.M.; Dunbar, B.; Wackerman, A.; Hodgin, S. Regenerative design: The LENSES Framework for buildings and communities. Build. Res. Inf. 2012, 40, 112-122. [CrossRef]

32. Plaut, J.M.; Dunbar, B.; Gotthelf, H.; Hes, D. Regenerative Development through LENSES with a case study of Seacombe West. Environ. Des. Guide 2016, 88, 1-19.

33. Nobe, M.C.; Greenwell, C. Moving Operations and Maintenance Practices of Existing Buildings beyond Sustainability: A Case Study of the LENSES Framework during Post Occupancy. Int. J. Constr. Educ. Res. 2016, 12, 122-141. [CrossRef]

34. CLEAR. The LENSES Rubrics; Centre for Living Environments and Regeneration: Fort Collins, CO, USA, 2016.

35. Du Plessis, C. Towards a regenerative paradigm for the built environment. Build. Res. Inf. 2012, 40, 7-22. [CrossRef]

36. Gladwin, T.N.; Newburry, W.E.; Reiskin, E.D. Why is the northern elite mind biased against community, the environment, and a sustainable future? In Environment, Ethics and Behaviour: The Psychology of Environmental Valuation and Degradation; Bazerman, M.H., Messick, D.H., Tenbrunsel, A.E., Wade-Benzoni, K.A., Eds.; Lexington Books: Lanham, MD, USA, 1997; pp. 234-274.

37. CLEAR. LENSES Overview Guide; Centre for Living Environments and Regeneration: Fort Collins, CO, USA, 2018.

38. Kashkooli, S.; Ali, M.; Mahya, P.; Habibi, A.; Hamid, R.S. Developing of evolution analysis algorithms in regenerative design and decision-making; Demonstrated through a case study in Shiraz, Iran. In Proceedings of the Creative Construction Conference, Ljubljana, Slovenia, 30 June-3 July 2018; pp. 862-869.

39. Ludwig, F. Baubotanik: Designing with Living Material. In Materiality and Architecture, 1st ed.; Löschke, S.K., Ed.; Routledge: New York, NY, USA, 2016; pp. 176-187.

40. Harrison, R.D.; Chong, K.Y.; Pham, N.M.; Yee, A.T.K.; Yeo, C.K.; Tan, H.T.W.; Rasplus, J.Y. Pollination of Ficus elastica: India rubber re-establishes sexual reproduction in Singapore. Sci. Rep. 2017, 7, 11616. [CrossRef]

41. Guevara, S.; Laborde, J.; Sánchez-Rios, G. Rain forest regeneration beneath the canopy of fig trees isolated in pastures of Los Tuxtlas, Mexico. Biotropica 2004, 36, 99-108. [CrossRef]

42. Upadhaya, K.; Thapa, N.; Lakadong, N.J.; Saroj, K.; Barik, K.; Sarma, K. Priority areas for conservation in northeast India: A case study in Meghalaya based on plant species diversity and endemism. Int. J. Ecol. Environ. Sci. 2013, 39, 125-136.

43. PWD. Achievement during Road Development Plan. 2015. Available online: http://megpwd.gov.in/roads. html (accessed on 2 March 2020).

44. Sarma, K. Land ownership, administration and status of forests of Khasi Hills autonomous district council of Meghalaya. NeBIO 2010, 1, 8-13. 
45. Sharma, A. Rethinking greenways design in context of sustainable development: Towards landscape synergism. In Proceedings of the Fábos Conference on Landscape and Greenway Planning, Budapest, Hungary, 8-10 July 2010; pp. 1-11.

46. Little, C.E. Greenways for America; JHU Press: Baltimore, MD, USA, 1995.

47. Sharma, A. Urban greenways: Operationalizing design syntax and integrating mathematics and science in design. Front. Archit. Res. 2015, 4, 24-34. [CrossRef]

48. Colding, J. Ecological land-use complementation'for building resilience in urban ecosystems. Landsc. Urban Plan. 2007, 81, 46-55. [CrossRef]

49. Hansen, R.; Pauleit, S. From multifunctionality to multiple ecosystem services? A conceptual framework for multifunctionality in green infrastructure planning for urban areas. Ambio 2014, 43, 516-529. [CrossRef] [PubMed]

50. Zöch, P. Laufen Manifesto for a Humane Design Culture. Topos. 2014. Available online: https://www. toposmagazine.com/laufen-manifesto-humane-design-culture/ (accessed on 17 March 2020).

51. Heringer, A. DESI Training Center: Self-sufficiency and Appropriateness in urbanNext. Available online: https://urbannext.net/desi-trainingcenter/ (accessed on 17 March 2020).

52. Hathaway, M.D. Agroecology and permaculture: Addressing key ecological problems by rethinking and redesigning agricultural systems. J. Environ. Stud. Sci. 2016, 6, 239-250. [CrossRef]

53. Ferreira, D.; Luso, E.; Fernandes, S.; Vaz, A.J.F.; Moreno, C.; Correia, R. Bioclimatic solutions existing in vernacular architecture. Rehabilitation techniques. In Proceedings of the PORTUGAL SB13-Contribution of Sustainable Building to Meet EU 20-20-20 Targets, Guimarães, Portugal, 30 October-1 November 2013; pp. 639-645.

54. Viji. India Biodiversity Awards. 2017. Available online: http://vikaspedia.in/energy/environment/ biodiversity-1/india-biodiversity-awards (accessed on 8 April 2019).

55. Khongthaw, M. Living Bridge Foundation. 2019. Available online: https://www.facebook.com/Living-BridgeFoundation-952519918242973/ (accessed on 8 April 2019).

(C) 2020 by the authors. Licensee MDPI, Basel, Switzerland. This article is an open access article distributed under the terms and conditions of the Creative Commons Attribution (CC BY) license (http://creativecommons.org/licenses/by/4.0/). 